\title{
Sea-ice tracking on the east coast of Ganada using NOAA AVHRR imagery
}

\author{
T. Heacock, T. Hirose, F. Lee, \\ Noetix Research Inc., 904-280 Albert St, Ottawa, Ontario, Canada K1P 5 G8 \\ M. MANORE \\ Canada Centre for Remote Sensing, 1547 Merivale Rd, Ottawa, Ontario, Canada K1A 017 \\ AND B. RAMSAY \\ Ice Centre, Environment Canada, 373 Sussex Dr., Ottawa, Ontario, Canada K1A OH3.
}

\begin{abstract}
An Ice Tracking System (ITS) is under development which will automatically extract ice kinematic information from time sequential imagery over Canadian waterways. NOAA AVHRR data are routinely collected at the Ice Centre Environment Canada (ICEC) and are a valuable data source for operational ice analysis and forecasting. For this study AVHRR data were collected between January and February 1992 over the Grand Banks of Newfoundland. The requirement for cloud-free data limited its use. Multiple images over short time intervals were available for a one to two day period, however these were followed by gaps of three to four days. On days when imagery was available synoptic conditions were always similar favouring a southeasterly ice drift. The east coast of Canada is a very difficult ice environment in which to extract accurate ice motion. The ice regime consists mainly of young ice types exhibiting very dynamic behaviour. To the NOAA sensor the ice cover can appear viscous and featureless. The inaccuracies in the extracted ice kinematic information was attributed to positional errors with the input data and the inability of the tracking algorithm to identify correctly the same features on time sequential images. Geocoding inaccuracies, a result of the systematic geocoding process, had an average error of $2.7 \mathrm{~km}$. Algorithm inaccuracies, a result of incorrect matching, had an average error of $2.45 \mathrm{~km}$.
\end{abstract}

\section{INTRODUCTION}

Filey and Rothrock (1986) described a sea-ice tracking algorithm, based on two-dimensional area correlation of sample pixel intensity arrays, that will derive ice motion from time-sequential remotely sensed imagery. Hirose and McNutt (1987) proposed a modified version of the algorithm to overcome limitations encountered in more difficult ice tracking situations. An Ice Tracking System (ITS) based on this algorithm is under development as part of a joint project between the Canada Centre for Remote Sensing (CCRS) and the Ice Centre Environment Canada (ICEC). The ITS will be used operationally at ICEC to generate sea-ice kinematic information over navigable Canadian waterways. In an operational environment the ITS will be required to extract efficiently the ice motion between sequential image scenes with minimal errors, and operate in different ice regimes using data acquired from a variety of sensors without human intervention.

Several remote sensing systems, including NOAA AVHRR (Advanced Very High Resolution Radiometer), aircraft radar (Synthetic Aperture Radar and Side Looking Airborne Radar), as well as DMSP SSM/I
(Special Sensor Microwave Imager), provide information for operational ice analysis and forecasting at ICEC. Both the AVHRR and SAR provide data sources fier deriving ice kinematic information. SAR imagery with its allweather capability and high resolution provide fine detail for resolving ice features. Ice tracking with SAR imagery can provide accurate sea-ice dynamics information on a tactical scale for shipping operations. However current SAR data have a limited area of coverage (i.e. ERS-1 with a $100 \mathrm{~km}$ swath) and repeat coverage (every three days in the ice orbit). AVHRR imagery on the other hand with its regular wide area coverage of Canadian waterways provides a continuous record of sea-ice conditions. Ice tracking with AVHRR imagery can be used in synoptic scale analysis for generating climatological sea-ice drift products.

Automated tracking of sea ice has been successfully accomplished in the high Arctic using both relatively coarse resolution NOAA AVHRR imagery, and higher resolution SAR imagery. To date however, successful automated sea-ice tracking in the marginal ice zone off the east coast of Newfoundland and Labrador has been limited to SAR imagery. The characteristics of the sea ice regime on the east coast differ markedly from those of the 
high Arctic. Large multi-year and thick first-year ice floes $(>10 \mathrm{~km})$ are ubiquitous in high Arctic imagery. The ice cover is characterized by the presence of distinct lead and ridge patterns illustrating a high degree of structure. In contrast, sea ice off Newfoundland and Labrador consists mainly of first-year ice that has been transported to the region along the Labrador current, or thin ice formed in situ. Wave action and storm activity break up the ice into small $(<15 \mathrm{~m})$ floes.

The combined character of the east coast ice regime and the NOAA sensor impose difficulties to the Ice Motion Algorithm (IMA). The east coast ice regime can appear featureless to the NOAA sensor due to its resolution ( $1 \mathrm{~km}$ at nadir). Because the internal ice structure is unresolvable, the IMA must be able to distinguish and track on the larger scale features of the ice pack. Furthermore, the dynamic nature of these features, in both shape and signature, impose constraints on the maximum allowable time interval between image pairs if successful matching is to be accomplished. Finally, NOAA being an optical sensor means that AVHRR imagery suffers from frequent contamination by cloud cover. The results of a previous evaluation of AVHRR imagery to track ice motion in the Beaufort Sea (Noetix, 1991) highlighted the detrimental effect that cloud and fog obstructions can have on the algorithm's ability to find and propagate matches, which will ultimately affect the operational utility of this data source for ice tracking.

In this paper, the utility of using NOAA AVHRR imagery to provide reliable and regular ice motion information is evaluated for a two month period from 1 January to 29 February 1992 over a region off the east coast of Newfoundland. All available imagery were collected and used in this study to answer the following questions:

- What is the amount of usable data during the period of study, and their impact on providing a continuous ice movement record?

- What is the magnitude of error in the ice kinematic analysis?

- When acceptable imagery is found, what is the impact of ice conditions and the presence of cloud with ice on the ability to track features?

The second section describes the data collection and preprocessing of the imagery prior to input into the Ice Tracking System. The third section describes the Ice Motion Algorithm. The fourth section describes the usable data sets and their utility for monitoring ice movement. Errors in deriving the ice displacement and velocity are examined in the fifth section and a more detailed analysis of the effect of ice type and cloud is provided in the final section.

\section{DATA COLLECTION AND PROGESSING}

NOAA AVHRR data collected and preprocessed at ICEC as part of standard operations were used as input into the ITS. Digital AVHRR data are received at ICEC in real-time through METSIS, a meterological communication system, from HRPT (High Resolution Picture
Transmission) receiving stations. Channels 1 (visible) through 4 (thermal IR) from the NOAA11 and NOAAl2 satellites are collected over the current operational regions with every overpass of the satellite. During winter the region of operational activity extends from Davis Strait $\left(68^{\circ} \mathrm{N}\right)$ down the Labrador coast to the Gulf of St Lawrence $\left(46^{\circ} \mathrm{N}\right)$. The repeat cycle for each satellite is 12 hours enabling imagery to be acquired roughly every six hours over the east coast of Canada. Upon ingestion at the Ice Centre the data are automatically cut into predefined sub-regions or sectors, geo-referenced and then enhanced within the Ice Data Integration and Analysis System (IDIAS) (Falkingham, 1991). Satellite ephemeris data are used to perform systematic geocoding on the imagery. The geocoding process is carried out by the Geocoded Image Correction system (GICS) software, a component of Macdonald Dettwiller's Meridian Image Analysis Software (MDA, 1991). Ephemeris data arrive with each image and are retained within an orbit database. Since the ephemeris data are updated only periodically, approximately every seven days, their accuracy degrades with time. The maintenance of a historical orbit database provides the capability to generate (or extrapolate) position and attitude information. Once geocoded, the image data are resampled to a uniform $1 \mathrm{~km}$ pixel grid to account for cross-track and along-track distortions, and mapped to a Lambert Conformal projection. The NOAA imagery sectors defined within the IDIAS system cover a geographic area approximately $1000 \mathrm{~km}$ by $1000 \mathrm{~km}$, centred over geographic areas of operational activity. Single channel enhancements include histogram equalisations and linear contrast stretches and multichannel enhancements include band ratioing.

As part of a larger study being conducted by the investigators, imagery covering the entire Canadian east coast waters were examined from January and February 1992. The area is subdivided into five sectors. Imagery was collected based on image quality, amount of cloud cover and availability of sequential image sets. Automatically enhanced imagery from band 4 (equalized and stretched) was processed through the Ice Tracking System. Results from imagery acquired from one sector covering the Grand Banks region off Newfoundland, centred about $49^{\circ} \mathrm{N}$ and $53^{\circ} \mathrm{W}$ are described in this paper. Image data collected off Newfoundland at the southernmost extent of the east coast ice regime provided a very dynamic and difficult ice environment with which to evaluate the ITS.

\section{TRACKING ALGORITHM DESCRIPTION}

The Ice Motion Algorithm (IMA) calculates ice displacements from time sequential imagery in a five step procedure; each step is referred to as a phase. The parameter settings used in this study for each phase are shown in Table 1. Phase 1 reduces the resolution of the input images. Fewer pixels means a faster processing time in the following phases. Phase 2 identifies a small number of initial matches. Phase 3 uses the initial matches found in phase 2 to guide the search for more matches. Phase 4 uses the results of phase 3 to guide a more detailed search 
Table 1. Parameter settings for the NOAA AVHRR east coast data sets

Phase 1 Phase 2 Phase 3 Phase 4 Phase 5

\begin{tabular}{lccccc}
$\begin{array}{l}\text { Number of } \\
\text { reductions }\end{array}$ & 0 & - & - & - & - \\
$\begin{array}{c}\text { Processing pixel } \\
\text { size }\end{array}$ & $1 \mathrm{~km}$ & - & - & - & - \\
$\begin{array}{l}\text { Partition size } \\
\% \text { Candidate }\end{array}$ & - & $30 / 60$ & $6 / 6$ & $6 / 6$ & - \\
$\quad$ selected & & $1 \%$ & $1 \%$ & $1 \%$ & - \\
$\begin{array}{l}\text { Grid cell size } \\
\begin{array}{c}\text { Correlation } \\
\text { window size }\end{array}\end{array}$ & - & $6 / 12$ & $6 / 12$ & $6 / 12$ & - \\
$\begin{array}{c}\text { Correlation } \\
\text { threshold }\end{array}$ & - & 9 & 9 & 9 & - \\
& & 0.7 & 0.7 & 0.5 & 0.5 \\
\hline
\end{tabular}

for matches. Finally, in phase 5 the resolution of the images is returned to the original level providing more accurate results.

An overview of the dataflow and processing scheme of the ice motion algorithm is as follows. In phase 1 multiple resolution images are generated from each of the original input scenes. A coarse resolution image is created by low pass filtering and subsampling of the original input image. The resulting coarse resolution image is input into phase 2 through 4. The number of reductions the input image goes through will depend upon the input image pixel resolution and the image ice characteristics. In this study no reductions were performed and the full resolution of the imagery used to identify and track ice features, due to

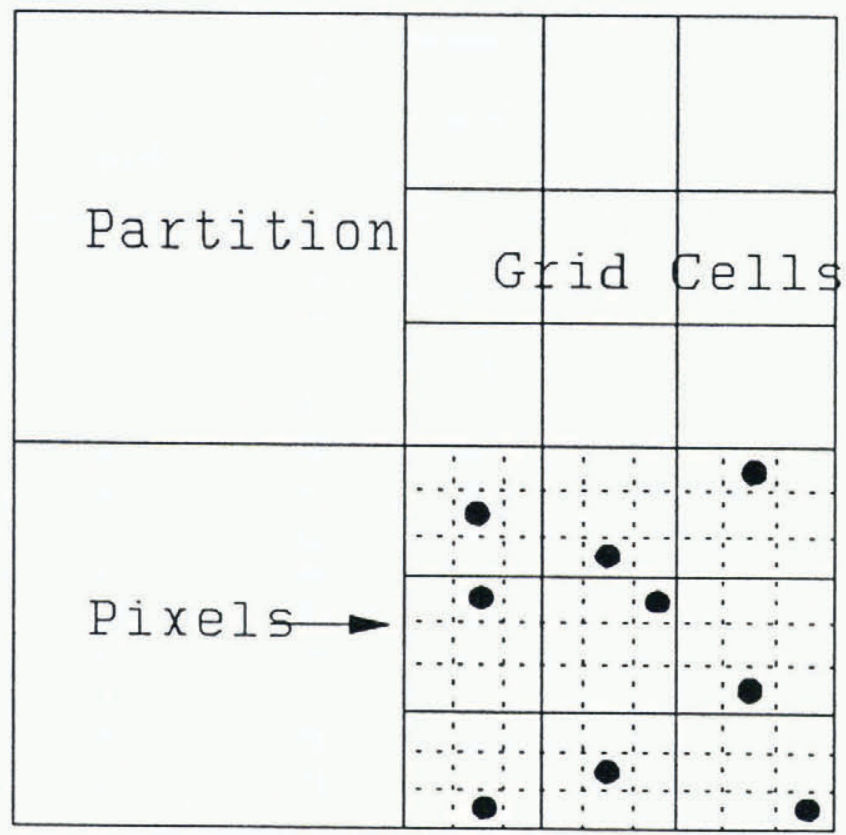

Fig. 1. Relationship between partitions, grid cells and pixels within the IMA. the $1 \mathrm{~km}$ input scene resolution and the thin ice types observed on the east coast.

After phase 1 the coarser resolution or working level images from each pair is high pass filtered. The filter is designed to highlight corners of floes and ridges in the ice providing candidate locations in the imagery.

The purpose of phase 2 is to find a few initial matching locations evenly spread over the coarse resolution image pair in a timely fashion. Three matching strategies are possible, one based on two-dimensional area correlation, one based on feature matching, and a third based on manually selecting matches. Only the area correlation matching strategy was examined in this study.

Area correlation involves comparing the array of pixel intensities surrounding a candidate point from the reference image with an array of pixel intensities from a second, or match image scene. A $9 \times 9$ pixel array was used in this study. A low correlation value corresponds to 0 and an exact match is 1.0. If the arrays or areas are similar a high correlation results. A detailed methodology for tracking sea ice using this technique is described in Hirose and McNutt (1987).

To implement the area correlation technique efficiently, images are partitioned into non-overlapping blocks, or partitions. Each partition is then further subdivided by a grid. Each cell within that grid is made up of a matrix of pixels. Figure 1 illustrates the relationship between partitions, grid cells and pixels. The imnage is divided by four partitions. Each partition is subdivided by nine grid cells each made up of nine pixels. Each grid cell can store one candidate, or match. Thus match points must be at least one grid cell apart. Grid cell sizes of 6 by 6 and 12 by 12 pixels with corresponding partition sizes of 30 by 30 and 60 by 60 pixels respectively were examined in this study.

Phase 3 propagates the match field by finding a match for locations over the entire image at a fine spacing. Beginning at the locations initialized in phase 2, a match for each of its neighbours on the reference scene is searched for on the second image. In order to reduce the number of locations to test on the second image, we assume that the neighbours tend to move in the same direction with a similar displacement as the initialized location. The heuristic is used to guide the search for matches of the neighbours. A small search area centred on the predicted location is cross correlated with the reference location and the best match (highest correlation) is compared with an acceptance threshold. If it is greater than the threshold it is assigned as a matching pair, otherwise no match is made. The process is repeated until no new matches are found. A high correlation threshold $(0.7)$ is used to inhibit the propagation of incorrect matches which may have occurred in the initialization phase.

Prior to leaving phase 3 , an attempt is made to detect and eliminate incorrect matches. It is assumed that locations in a local neighbourhood will move in similar way (in both direction and magnitude). If a point does not move like the local motion field, it is removed from the matched locations list.

Phase 4 is identical to phase 3 except the acceptance threshold is lowered enabling more locations to be matched. Phase 5 refines the positional accuracy of the 


\begin{tabular}{||c|c|c|c|c|c|c|c|c|c|c|c|c|c|c|c|c||}
\hline \multicolumn{3}{|c|}{ January } & 1 & 2 & 3 & 4 & 5 & 6 & 7 & 8 & 9 & 10 & 11 & 12 & 13 & 14 \\
\hline 15 & 16 & 17 & 18 & 19 & 20 & 21 & 22 & 23 & 24 & 25 & 26 & 27 & 28 & 29 & 30 & 31 \\
\hline \multicolumn{3}{|c|}{ February } & 1 & 2 & 3 & 4 & 5 & 6 & 7 & 8 & 9 & 10 & 11 & 12 & 13 & 14 \\
\hline 15 & 16 & 17 & 18 & 19 & 20 & 21 & 22 & 23 & 24 & 25 & 26 & 27 & 28 & 29 & & \\
\hline
\end{tabular}

Fig. 2. Days of acceptable image quality (shaded).

matched pairs by finding their corresponding locations on each of the higher resolution images. This was not applied in this study because processing was performed at the original image resolution.

\section{USABLE DATA FOR ICE TRACKING}

A daily record of ice motion over time is desired by users in order to derive ice displacement and ice velocity. Although the NOAA series of satellites is capable of providing multiple images over a site in a day, cloud cover often obscures the ice field and can limit the data's usefulness in providing reliable daily ice motion information.

Figure 2 illustrates the days when imagery was judged acceptable for ice tracking during the study period, (shaded area refers to conditions favourable to image acquisition). An image was considered acceptable when $80 \%$ of the ice cover was cloud free. Over the 60 day study period, there were 14 days ( $23 \%$ of total) when acceptable imagery was found. In January, the image record is sparse with 5 days of usable data and a 17 day period where cloud cover continuously obscured the ice field. In February, the record is more regular with useable data collected every three to five days.

For each of the 14 days, multiple images over the study area were available and permitted ice tracking to be performed over a short time interval. However, when the time separation exceeded 48 hours, tracking was not possible. This is attributed to the dynamic nature of the ice, and the ice features visible in one sequence of images were obscured by cloud in imagery from the later period.

In this study, four sets of sequential images, a total of 13 scenes, were collected over the January-February time frame. Table 2 provides a list of the imagery collected and their acquisition parameters and scene characteristics. The imagery is treated in four groups (labelled alphabetically corresponding to periods of frequent temporal coverage). The data sets provided a range of time intervals between image pairs ( 5 to $24 \mathrm{hrs}$ ) and complete and partial cloud cover (0 to $55 \%$ ) with which to evaluate the utility and accuracy of ice tracking with AVHRR data.

The mean synoptic conditions were similar on all days when acceptable imagery was obtained. A low pressure

Table 2. Data-set characteristics

\begin{tabular}{|c|c|c|c|c|c|c|c|c|}
\hline Ref. & Acquisition & Acquisition & Image centre & \multicolumn{5}{|c|}{ Scene characteristics ${ }^{1}$} \\
\hline number & date & time & (lat.-long.) & $\begin{array}{c}\% \\
\text { cloud }\end{array}$ & $\begin{array}{c}\% \\
\text { land }\end{array}$ & $\begin{array}{c}\% \text { open } \\
\text { water }\end{array}$ & $\begin{array}{l}\% \\
\text { ice }\end{array}$ & $\begin{array}{c}\% \text { ice } \\
\text { partially } \\
\text { obscured }^{2}\end{array}$ \\
\hline
\end{tabular}

\begin{tabular}{lllllllrrr} 
A1 & 23 Jan. '92 & $06: 39$ & $48.919 \mathrm{~N}$ & $51.809 \mathrm{~W}$ & 55 & 20 & 5 & 20 & 5 \\
A2 & 28 Jan. '92 & $11: 11$ & $48.930 \mathrm{~N}$ & $52.002 \mathrm{~W}$ & 50 & 20 & 10 & 20 & 0 \\
A3 & 23 Jan. '92 & $18: 14$ & $48.818 \mathrm{~N}$ & $52.087 \mathrm{~W}$ & 50 & 20 & 15 & 10 & 40 \\
B1 & 28 Jan. '92 & $17: 14$ & $48.858 \mathrm{~N}$ & $52.186 \mathrm{~W}$ & 60 & 20 & 5 & 15 & 60 \\
B2 & 28 Jan. '92 & $22: 37$ & $49.000 \mathrm{~N}$ & $52.000 \mathrm{~W}$ & 55 & 20 & 5 & 20 & 5 \\
$\mathrm{C} 1$ & 15 Feb. '92 & $11: 27$ & $48.841 \mathrm{~N}$ & $52.103 \mathrm{~W}$ & 50 & 20 & 15 & 15 & 45 \\
$\mathrm{C} 2$ & 15 Feb. '92 & $22: 59$ & $48.943 \mathrm{~N}$ & $52.110 \mathrm{~W}$ & 55 & 20 & 5 & 20 & 30 \\
$\mathrm{C} 3$ & 16 Feb. '92 & $06: 58$ & $48.908 \mathrm{~N}$ & $52.004 \mathrm{~W}$ & 50 & 20 & 0 & 30 & 15 \\
$\mathrm{C} 4$ & 16 Feb. '92 & $12: 48$ & $48.826 \mathrm{~N}$ & $52.014 \mathrm{~W}$ & 50 & 20 & 15 & 15 & 20 \\
D1 & 24 Feb. '92 & $23: 09$ & $49.098 \mathrm{~N}$ & $52.185 \mathrm{~W}$ & 45 & 20 & 0 & 30 & 15 \\
D2 & 25 Feb. '92 & $06: 51$ & $48.830 \mathrm{~N}$ & $52.034 \mathrm{~W}$ & 45 & 20 & 0 & 35 & 30 \\
D3 & 25 Feb. '92 & $11: 16$ & $48.896 \mathrm{~N}$ & $51.799 \mathrm{~W}$ & 50 & 20 & 0 & 35 \\
D4 & 25 Feb. '92 & $22: 47$ & $48.827 \mathrm{~N}$ & $52.121 \mathrm{~W}$ & 45 & 20 & 0 & 35 \\
& & & & & & & 0 \\
\hline
\end{tabular}

\footnotetext{
${ }^{1}$ Visually estimated.

${ }^{2}$ Ice features are partly visible through the cloud cover.
} 
Table 3. Synoptic conditions during imagery acquisition

Date Geostrophic flow $^{3} \quad$ Predominant systems ${ }^{3}$

0000 and $1200 \mathrm{~h} \mathrm{Z}$
Peak wind speed
and direction $\quad \begin{gathered}\text { Average } \\ \text { temperatures }\end{gathered}$

${ }^{\circ} \mathrm{C}$
23 Jan. North-northwest $(0000 \mathrm{~h})$ West-southwest (1200 h)

$28 \mathrm{Jan}$. West-northwest $(0000 \mathrm{~h})$ West (1200 h)

15 Feb. West-northwest $(0000 \mathrm{~h})$ West (1200 h)

16 Feb. North-northwest $(0000 \mathrm{~h})$ Southeast $(1200 \mathrm{~h})$

24 Feb. West-northwest $(0000 \mathrm{~h})$ West-northwest $(1200 \mathrm{~h})$

25 Feb. Northwest $(0000$ h) West $(1200 \mathrm{~h})$
Strong low southeast of Greenland, weak low west of Baffin Island, strong high over New England, weak high over Nares Strait

Strong low east-southeast of Newfoundland, weak low over central Arctic, strong high over Beaufort Sea, weak high over New England

Strong low southeast of Greenland, weak low off Nova Scotia, weak high stretching from the Beaufort Sea to the Great Lakes

Broad lows over Great Lakes and southern Greenland/Baffin Bay, moderate highs east of Greenland and over Beaufort Sea

Low over north Atlantic and Iceland, broad high over Arctic and western Canada

Low over north Atlantic and Iceland, broad high over Arctic and western Canada

$\begin{array}{cc}\text { W-SW / } 38 \mathrm{kt}^{1} & -13.0^{1} \\ \mathrm{~W} / 29 \mathrm{kt}^{2} & -10.6^{2}\end{array}$

$\mathrm{W} / 25 \mathrm{Kt}^{1}$ $-24.9^{1}$ $\mathrm{W}-\mathrm{NW} / 23 \mathrm{kt}^{2} \quad-16.0^{2}$

$\begin{array}{cr}\mathrm{W} / 28 \mathrm{kt}^{1} & -22.3^{1} \\ \mathrm{~N} / 31 \mathrm{kt}^{2} & -11.0^{2} \\ & \\ \mathrm{E}-\mathrm{SE} / 25 \mathrm{kt}^{1} & -16.1^{1} \\ \mathrm{SE} / 35 \mathrm{kt}^{2} & -9.4^{2}\end{array}$

$\begin{array}{cc}\text { W-NW / } 30 \mathrm{kt}^{1} & -22.0^{1} \\ \mathrm{~W} / 23 \mathrm{kt}^{2} & -15.0^{2} \\ & \\ \mathrm{~W}-\mathrm{SW} / 30 \mathrm{kt}^{1} & -21.0^{1} \\ \mathrm{NW} / 22 \mathrm{kt}^{2} & -17.0^{2}\end{array}$

\footnotetext{
${ }^{1}$ Recorded at St Anthony's (northern extent of Newfoundland).

${ }^{2}$ Recorded at St John's (southern extent of Newfoundland).

${ }^{3}$ Extracted from the 1000 mbar pressure chart.
}

system located over the North Atlantic and a high pressure system located over the Arctic Ocean governed the wind field. These conditions favoured winds with a westerly or northwesterly component. The combined influence of winds of reasonable intensity and the southward flow of the Labrador current resulted in the ice drifting in a predominantly southeast direction. Table 3 lists the prevailing climatic conditions on the days when imagery was acquired.

The sea-ice extent on the east coast during the 199192 season was two to three weeks ahead of the mean as temperatures remained below normal throughout January and February, (operational ice briefings, ICEC). By early January the extent had reached latitude $50^{\circ} \mathrm{N}$, consisting of predominantly new and grey ice with some grey-white ice intermixed. Figure 3 illustrates the ice characteristics on 23 January (scene A1). By the end of February the ice extent had reached $47^{\circ} \mathrm{N}$, consisting of predominantly thin firstyear ice with some grey-white ice intermixed. Figure 4 illustrates the ice characteristics on 24 February (scene D2). The type of ice being tracked has important ramifications to an automated system as features composed of thin ice types will change shape

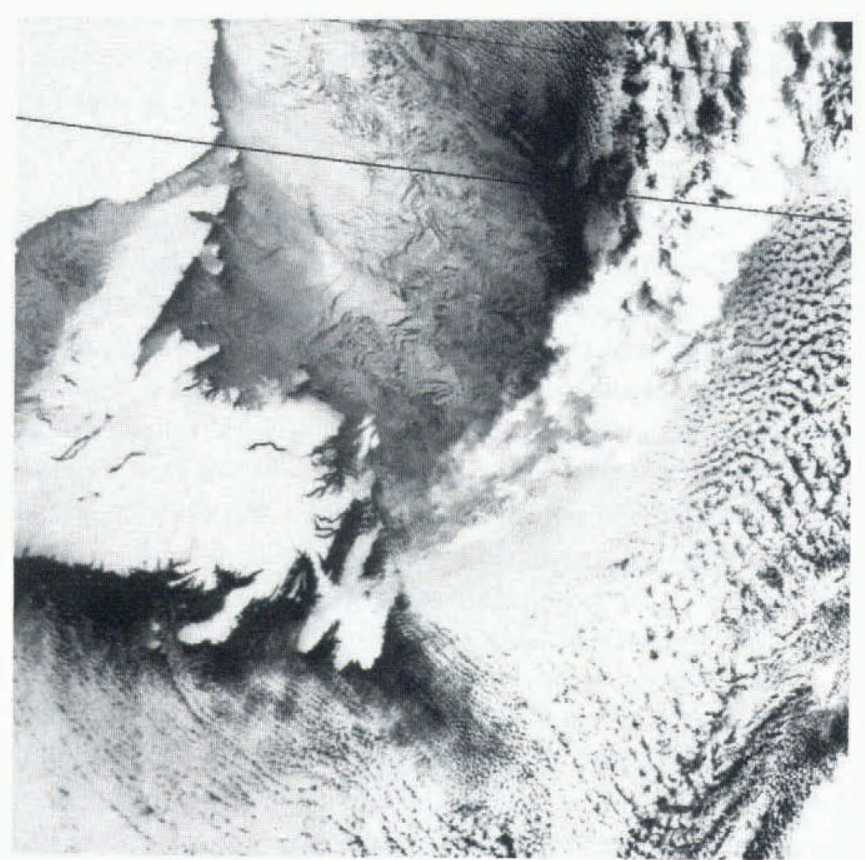

Fig. 3. 23 January 1992 (0639 UTC). 


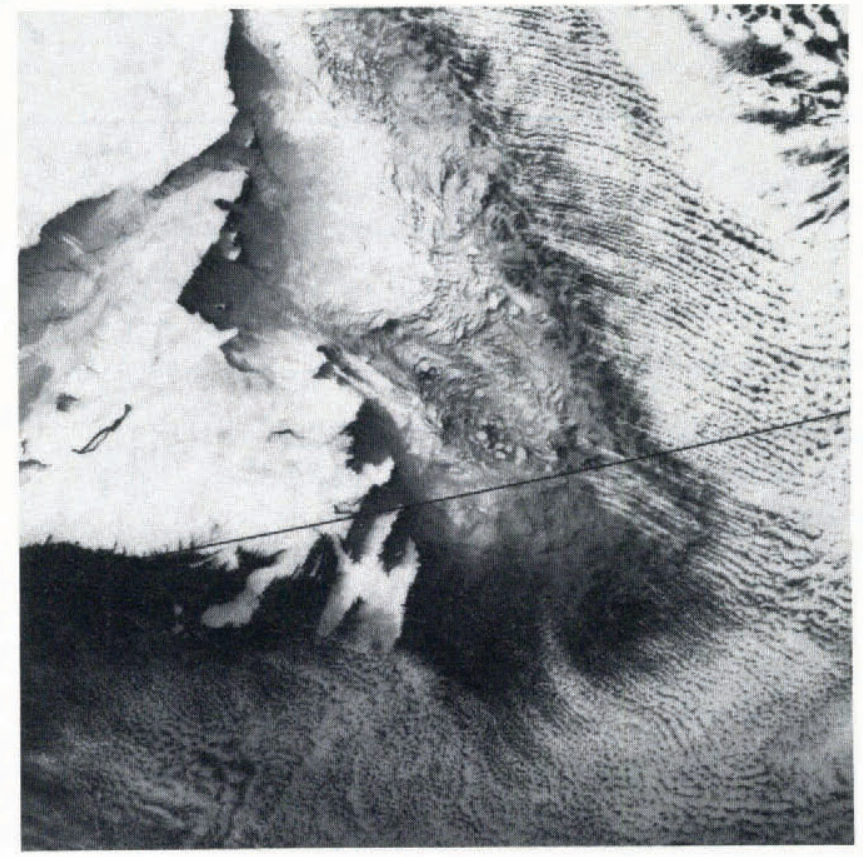

Fig. 4. 24 February 1992 (0651 UTC).

and appearance more rapidly than will thicker ice types. The synoptic conditions favourable to using AVHRR imagery for ice tracking combined with the thin ice types observed in this region resulted in scenes exhibiting highly dynamic motion. The net result was a relatively dispersed ice cover that has a viscous appearance to the sensor.

The time interval between image scenes will be critical if features are to be matched between scenes, particularly during the early part of the season.

\section{ERROR IN DERIVING ICE KINEMATIC INFOR- MATION}

Sources of error in the ice displacement and velocity measurements result from: (1) the scene-to-scene misregistration of the images, (2) the within-scene geometric distortion, and (3) the incorrect identification of the same ice feature by the tracking algorithm.

Scene-to-scene misregistration is a result of inaccurate ephemeris and altitude information as well as along-track timing errors which results in a difference between the actual location of the scene centre and the estimated scene centre based on an orbital prediction model. In this study, the average misregistration error observed for the data sets was $50 \mathrm{~km}$. An error of this magnitude is unacceptable for ice kinematic studies and required manual intervention for correction. A single feature common to image pairs was identified and one image translated to correspond to the other.

The manual correction procedure provides an accurate scene-to-scene registration at one point only. There will be some error associated with that point, which is dependent on the quality of the scene being registered, however in general selection of ground control points has an accuracy of one to two kilometres ( 1 or 2 pixels). Locations away from the common point were not accurately registered because of geocoding errors. This was made evident by observing the misregistration of land features (i.e. coastlines) when two images are overlayed.

The image misregistration after manual intervention was determined by selecting 53 random points covering visible land features and calculating the difference in pixel locations between shoreline image pixels and the overlain vector basemay coastline. The cartographic basemap shoreline was considered to represent the true shoreline location. The difference in pixel locations was estimated by measuring the $X$ and $Y$ displacements of common points, then calculating the length of the offset. If the images were co-registered, coastal features would be located at the same pixel location; if not, they were misregistration errors. The average calculated misregistration was $2.7 \mathrm{~km}(\alpha=2.08 \mathrm{~km})$, with a minimum error of $640 \mathrm{~m}$ and a maximum error of $9.1 \mathrm{~km}$.

The error attributable to the ice-tracking algorithm was determined by comparing the average displacement and direction determined by the algorithm with those obtained by manually identifying the features on pairs of iamges. $A$ and $p 1$ are the displacement and direction respectively obtained from the manual process. $B$ and $p 2$ are the displacements and direction respetively derived by the ice-tracking algorithm. The accuracy of the icetracking algorithm was then calculated using the cosine rule :

$$
\text { Error }=\sqrt{\left[A^{2}+B^{2}-2 A B \cos (p)\right]}
$$

where $A=$ magnitude of the actual displacement, $B=$ magnitude of the ice tracking displacement and $p=p 1-p 2$. The comparison of the average vector displacement was tested over a local area because the ice moved and was tracked as a rigid body over small localized areas.

\section{EFFECT OF IGE TYPE AND GLOUD ON DATA PROCESSING}

Tables 4 and 5 list the average manually extracted displacements $(\bar{M})$, the mean automatically extracted displacements $(\bar{T})$, the root-mean-square value of the displacement error (RMSE), the average extracted displacement differences $\left(\bar{D}_{\bar{x}}\right)$, the standard deviations $\left.\bar{D}_{\sigma}\right)$ of the displacement differences as well as the absolute minimum $\left(D_{\min }\right)$ and maximum $\left(D_{\max }\right)$ displacement differences observed within all sample vectors. Table 4 clearly demonstrates that total displacement errors resulting from both magnitude and direction errors averaged over all processed pairs were smaller when processed with grid size of 6 than a grid size of 12 . These results indicate that the estimated displacement errors ranged between 0.3 and $0.6 \mathrm{~km}$ for grid sizes 6 and 12 respectively, where the average observed vectors displacements were $21 \mathrm{~km}$. However errors can be as large as $8.5 \mathrm{~km}$ and $13 \mathrm{~km}$ (two standard deviations).

A grid cell size of 12 pixels by 12 pixels, from which one candidate match point may be selected, would restrict features selected by the algorithm to be approximately $12 \mathrm{~km}$ apart, due to the resolution of the sensor. The effective number of potential candidates in phase 2 and propagation candidates in subsequent phases 
$\mathrm{km}$

$\mathrm{km}$

$\begin{array}{llllllll}N & \bar{T}) & \bar{T} & \mathrm{RMSE} & \bar{D}_{\bar{x}} & \bar{D}_{\sigma} & D_{\min } & D_{\max }\end{array}$

Grid cell size 6

Grid cell size 12
$43 \quad 21.112$

$43 \quad 21.112$

\subsection{6}

20.534
2.011

4.515
0.310

0.602

$\begin{array}{lll}6.664 & 0.000 & 26.298\end{array}$

Table 5. Displacement errors (grid size 6)

\section{Ref. Match Time Mean displacemen \\ image image interval}

\section{Displacement error}

$\mathrm{km}$

RMSE $\quad \bar{D}_{\bar{x}} \quad \bar{D}_{\sigma} \quad D_{\min } \quad D_{\max }$

2.308
1.134
0.674
1.294
1.220
8.896
6.856
1.434
1.364
0.712
1.066

2.256
0.988
0.193
0.781
0.288
0.286
7.989
0.759
1.522
0.448
0.754

\subsection{6}

0.560

0.730

0.698

1.158

10.436

5.900

1.416

1.372

0.282

0.990
0.284

0.206

0.208

0.442

0.400

1.504

2.684

0.372

0.462

0.450

0.308
4.196

1.722

1.516

1.468

2.040

8.692

11.030

3.368

3.736

1.010

2.626 is thus reduced with the larger grid sizes. Therefore many "optimal" matching features will be missed due to the characteristics of the ice environment, which sometimes only illustrate subtle differences across and between scenes. Furthermore, matching will have a greater probability of missing or incorrectly selecting the true destination point as the effective area in which a match is searched for is increased.

The average displacement errors were calculated on a per image pair basis (Table 5) and the influence of image acquisition time intervals and scene and ice characteristics on total calculated error were examined. The results do not clearly indicate any significant variation in error between the scenes examined. However, it appears that ice motion vectors extracted from the February data sets (C and D) had a lower mean error than did ice motion vectors extracted from the January data sets (A and B). These results were expected since the February ice cover was more developed than the January ice cover and thus contained more distinguishable features, and would be subject to less variation between successive scenes. The effect of time intervals is less clearly defined by the results as the magnitude of the error remained relatively constant over the entire data set. The results indicate that matching accuracy is more a function of ice type or quality than of time interval.

Two exceptions to the suggested trend were observed in the results, A1-A3 and D1-D3, the pairs include both the early stage of ice progression (A) and the late stage (D). The fact that both pairs have a time interval of $1130 \mathrm{~h}$ is more of an anomaly than part of a trend. The error in the A1-A3 pair is most likely an effect of the time interval, strong winds were recorded (see Table 3 ) which would have caused significant variations between scenes in the shape of the features being tracked due to the young stage of ice development. Furthermore, there was also a significant increase in cloud cover between scenes which may have caused errors. The D3-D4 pair seems to be the result of one of the local area samples out of the five which exhibited six times as much calculated error as the 


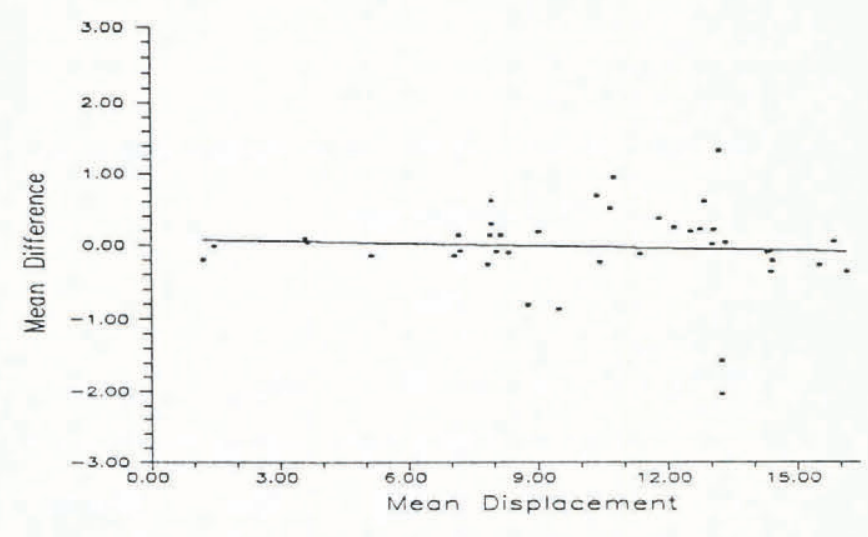

Fig. 5. Magnitude of mean displacement error. Grid cell size 6 by 6 pixels.

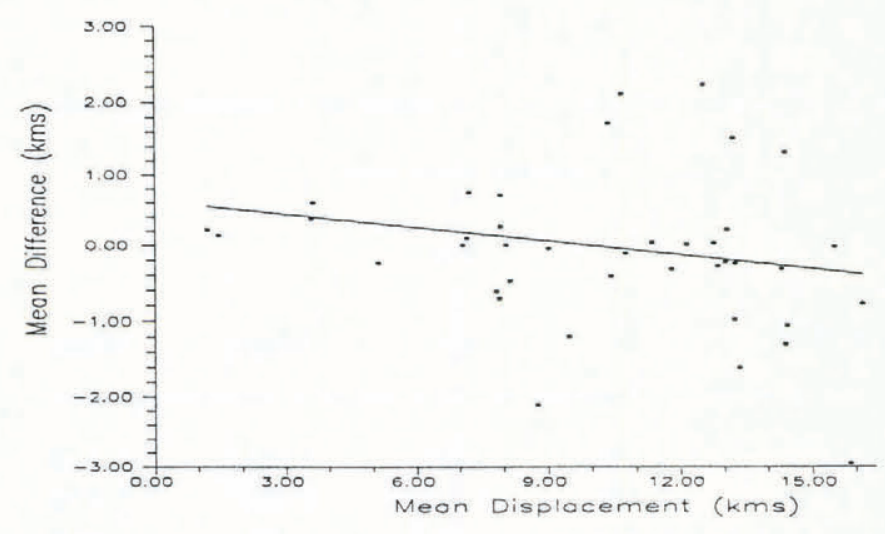

Fig. 6. Magnitude of mean displacement error. Grid cell size 12 by 12 pixels.

Table 6. Efficiency of land and cloud matching

\begin{tabular}{rrrrr}
$\begin{array}{c}\text { Grid cell } \\
\text { size }\end{array}$ & \multicolumn{2}{c}{ Land matching } & \multicolumn{2}{c}{ Cloud matching } \\
& $<12 \mathrm{~h}$ & $>12 \mathrm{~h}$ & $<12 \mathrm{~h}$ & $>12 \mathrm{~h}$ \\
\hline & & & & \\
\hline 6 & $49 \%$ & $41 \%$ & $6 \%$ & $5 \%$ \\
12 & $60 \%$ & $39 \%$ & $4 \%$ & $3 \%$ \\
\hline
\end{tabular}

others due to $60^{\circ}$ variation in direction between the manually extracted vectors and the IMA vectors. This sample was extracted near the ice-ocean margin where the ice is the most dynamic and subject to variation between scenes. Removal of that one observation decreased the error $\left(\bar{D}_{\bar{x}}\right)$ from 8.896 to $2.205 \mathrm{~km}$, which is still high, although more in line with the results of the entire data set.

The magnitude of the mean displacement error for the IMA vectors processed using processing grid sizes of 6 and 12 can be seen in Figures 5 and 6, respectively. Displacement errors or inaccuracies increase with the length of vector being matched. The slope of the best fit line and the spread of the displacement differences around that line indicate that the magnitude of the error is much less when processing with a grid size of 6 than a grid size of 12. The slope of the lines were 0.011 and 0.074 for grid sizes 6 and 12 respectively, suggesting errors of \pm 11 and $\pm 74 \mathrm{~m}$ in the estimate of displacement for each $1 \mathrm{~km}$ of ice motion, significant at the 0.05 level.

\section{INFLUENCE OF GLOUD AND LAND ON PROGES- SING TIME AND IGE TRACKING}

In an operational environment the ITS must automatically generate ice motion products with little or no human intervention. With automatic processing the vector field propagated over the entire image scene including cloud, land, open water and ice features. On average cloud features covered $50 \%$ of the scene, land features $20 \%$, open water features $5 \%$ and ice features $25 \%$ of the scene (see Table 2). As a mean percentage of the total number matches found, $25 \%$ were on cloud features, $40 \%$ on land features, $5 \%$ on open water, and $35 \%$ on ice features. Table 6 illustrates the mean per cent of matches from the total possible (one match per grid cell) that occurred on the land and cloud features for time intervals less than and greater than $12 \mathrm{~h}$. The table clearly illustrates that matches on land features consumed a significant proportion of the total processing requirements. Cloud matching on the other hand had a negligible influence. Time intervals also had the obvious effect of increasing the total number of matches found on all features. As information is only truly desired over the ice, masking the land and cloud features would result in both improvements in processing efficiencies and errors, both total errors over the scene as well as errors propagated into the ice along the land-ice and cloud-ice margins. However, land matches can provide information on the scene-to-scene geopositioning inaccuracies, and therefore some combination mask may be more appropriate.

\section{CONGLUSION AND RECOMMENDATIONS}

The utility of NOAA AVHRR and an automated icetracking algorithm for providing users with accurate and regular ice kinematic information was examined for a two month period from January to the end of February 1992, off the east coast of Newfoundland.

The availability of cloud-free sequential data of the same ice limited the use of the imagery. Typically, multiple images were available for a one-to-two day period and could be used to track the ice movement, but gaps of three to four consecutive days with persistent cloud cover were observed. In many instances, the time interval for tracking the same ice feature extended beyond the three-to-four day gap because sea-ice features present in one image were obscured by cloud on the other, although ice was visible on both scenes. These results, for the limited period of study, suggest that NOAA AVHRR will provide only sporadic ice kinematic information. When available, however, ice velocity can be determined over short time intervals (i.e. $6 \mathrm{~h}$ ) because of the frequent revisit by the two NOAA satellites. This would be 
appropriate for verification and initialisation of ice models.

The accuracy of the ice kinematic information is limited by the ability of the tracking algorithm to identify the same features on sequential images, and the registration accuracy of the imagery itself. The preprocessed geocoded product used by the tracking algorithm has two error components: the estimated location of the scene centre, and within-scene distortion after geocoding. The former was observed to introduce an error of $50 \mathrm{~km}$ and required manual intervention to overcome this problem. Inaccurate geocoding within a scene introduced an average error of $2.7 \mathrm{~km}$ after the scene centres were corrected. Better earth models and/or the use of the displacement of land features derived from the algorithm could be used to eliminate this error.

If the errors in the preprocessed imagery were minimized, the only error remaining would be a result of mismatches by the algorithm. In this study, the algorithm had an average error of $2.45 \mathrm{~km}$, or $1.84 \mathrm{~km}$ without error recorded in data set D3-D4.

The presence of cloud did not significantly affect the ability of the algorithm to extract the ice kinematic field, nor impact the processing time. However, the algorithm did track cloud motion since these areas were not masked out. In the future, it would be desirable to identify automatically the location of clouds and remove them for cosmetic reasons.

\section{ACKNOWLEDGEMENTS}

The authors thank the Canada Centre for Remote
Sensing, Department of Energy Mines and Resources for the use of their facilities and to the Ice Centre Environment Canada for the NOAA AVHRR data. This work was supported through funding from the Radar Data Development Plan and the Panel on Energy Research and Development.

\section{REFERENCES}

Falkingham, J. C. 1991. Operational remote sensing of sea ice. Arctic, 44, Supplement 1, 21-33.

Filey, M. and D. A. Rothrock. 1986. Extracting sea ice data from satellite imagery. IEEE Trans. Geosci. Remote Sensing, 24, 849-854.

Hirose T. and L. McNutt. 1987. Toward an automated ice tracking algorithm. Report prepared for the Canada Centre for Remote Sensing. Ice Applications Group. Ottawa, Noetix Research.

Macdonald Detweiter and Associates Ltd. 1991. IDIAS reference manual: ID-MA-MDA-SY-0010. Revision 2/0. Vancouver, Canada.

Noetix Research. 1991. Evaluation of an ice tracking algorithm. Report prepared for the Canada Centre for Remote Sensing. Ice Applications Group and the Ice Centre Environment Canada. Ottawa, Noetix Research.

The accuracy of references in the text and in this list is the responsibility of the authors, to whom queries should be addressed. 